\title{
Knockdown of Beclin 1 inhibits vitamin K3-induced autophagy, but promotes apoptosis of human hepatoma SMMC-7721 cells
}

\author{
CHUANG YANG $^{1}$ and LI-OU HAN ${ }^{2}$ \\ ${ }^{1}$ Third Department of General Surgery, the Second Affiliated Hospital of Harbin Medical University, Harbin 150086; \\ ${ }^{2}$ Department of General Surgery, the First Affiliated Hospital of Harbin Medical University, Harbin 150001, P.R. China
}

Received May 3, 2010; Accepted July 22, 2010

DOI: $10.3892 / \mathrm{mmr} .2010 .347$

\begin{abstract}
The aim of the present study was to investigate the effects of Beclin 1 knockdown on spontaneous and vitamin $\mathrm{K}_{3}$ $\left(\mathrm{VK}_{3}\right)$-regulated autophagy, survival and apoptosis in human hepatocarcinoma SMMC-7721 cells, and to explore the potential mechanisms underlying the action of Beclin 1 knockdown in the processes of autophagy and apoptosis. A recombinant plasmid-expressing small interfering RNA (siRNA) targeting Beclin 1 mRNA was constructed and introduced into SMMC7721 cells. The expression of Beclin 1 was determined by reverse transcription-polymerase chain reaction and Western blotting. Subsequently, the impact of Beclin 1 knockdown on spontaneous and $\mathrm{VK}_{3}$-induced autophagy, survival and apoptosis was determined. The expression of cyclin D1, cyclindependent kinase 4 (CDK4), Bcl-2, Bcl-xL and the activation of caspase-3 were examined by Western blotting. Transfection with the plasmid for Beclin 1 siRNA expression dramatically down-regulated Beclin 1 expression in SMMC-7721 cells. The knockdown of Beclin 1 expression significantly inhibited spontaneous and $\mathrm{VK}_{3}$-induced autophagy, but did not affect spontaneous proliferation and apoptosis in SMMC-7721 cells in vitro. By contrast, the silencing of Beclin 1 expression significantly enhanced the inhibition of survival and proliferation by $\mathrm{VK}_{3}$, and promoted $\mathrm{VK}_{3}$-induced apoptosis by significantly down-regulating cyclin D1, CDK4, Bcl-2 and $\mathrm{Bcl}-\mathrm{xL}$ expression and enhancing caspase- 3 activation in SMMC-7721 cells in vitro. Our data indicate that Beclin 1 is a positive regulator of autophagy, but a negative regulator of $\mathrm{VK}_{3}$-induced apoptosis in human hepatoma cells.
\end{abstract}

Correspondence to: Dr Chuang Yang, Third Department of General Surgery, the Second Affiliated Hospital of Harbin Medical University, No. 246 Xuefu Road, Nangang, Harbin 150086, P.R. China

E-mail:phdych@163.com

Dr Li-Ou Han, Department of General Surgery, the First Affiliated Hospital of Harbin Medical University, No. 23 Youzheng Street, Nangang, Harbin 150001, P.R. China

E-mail: hmy3210@126.com

Key words: vitamin $\mathrm{K}_{3}$, human hepatoma cells, transfection, RNA interference, Beclin 1, autophagy, apoptosis

\section{Introduction}

Vitamin $\mathrm{K}_{3}$ (2-methyl-1,4-naphthoquinone; $\mathrm{VK}_{3}$ ), a synthetic version of vitamin $\mathrm{K}$, is a potent inducer of oxidative stress. Numerous studies have demonstrated that $\mathrm{VK}_{3}$ inhibits the growth of multiple types of tumor cells both in vitro and in vivo (1-3). $\mathrm{VK}_{3}$ induces $\mathrm{G} 1$ cell cycle arrest by downregulating the expression of cyclin D1 and cyclin-dependent kinase 4 (CDK4) in hepatocellular carcinoma cells $(1,4)$. Other studies have indicated that $\mathrm{VK}_{3}$ induces the caspasedependent apoptosis of tumor cells (5-7). Recently, vitamin K2-induced cell growth inhibition was attributed to the induction of autophagy formation in cholangiocellular carcinoma cells (8). However, the mechanisms underlying $\mathrm{VK}_{3}$-mediated tumor cell growth inhibition are poorly understood. Whether $\mathrm{VK}_{3}$ induces autophagy, and how the regulators of autophagy affect cell survival, proliferation and apoptosis in hepatocarcinoma cells have never been explored.

Apoptotic and autophagic cell death are two distinct forms of programmed cell death, which is closely associated with the development and progression of many diseases, such as neurodegenerative and autoimmune diseases, malignant tumors and pathogenic microorganism infections $(9,10)$. Cells undergoing apoptosis exhibit cell shrinkage, membrane blebbing, nuclear fragmentation, formation of apoptotic bodies, mitochondrial release of cytochrome $\mathrm{c}$ and massive caspase activation (11). By contrast, autophagic cell death is characterized by massive vacuolization in the cytoplasm with accumulation of autophagic vacuoles (AVs), but without chromatin condensation (12). During the autophagic process, some cytoplasmic components and organelles are sequestered within double-membrane vesicles, termed autophagosomes, and delivered to lysosomes for degradation. The degradation products are reused in cells, and these processes regulate the cell growth, embryonic development and pathogenesis of many diseases (13). Apparently, certain stimuli may activate the signaling pathways involved in both autophagy and apoptosis (14). Therefore, the discovery of molecules that regulate both autophagy and apoptosis may be of great significance in the development of drugs for the treatment of cancer. 
Beclin 1, the mammalian homologue of yeast Atg6/Vps30, is a haploinsufficient tumor suppressor (15). Mice carrying heterozygous disruption of the Beclin 1 gene suffer from a high incidence of spontaneous tumors, including hepatocellular carcinoma (16). Allelic loss of the Beclin 1 gene is commonly found in many of human malignant tumors, such as breast, ovarian and prostate cancer (17). Beclin 1 is an upstream critical regulator of various autophagy signaling pathways, and is responsible for mediating the formation of AVs (18). Moreover, the knockdown of Beclin 1 expression enhances Fas-induced apoptosis and doxorubicin-mediated aggravating mitochondrial permeabilization in HepG2 cells in vitro (19), while the overexpression of Beclin 1 augments the cis-diamminedichloroplatinum-induced apoptosis of gastric cancer MKN28 cells by enhancing caspase-9 activity (20). Therefore, Beclin 1 is a dual functional regulator of autophagy and apoptosis. However, whether Beclin 1 regulates $\mathrm{VK}_{3}$-mediated tumor cell growth inhibition has not been investigated.

This study aimed to examine the effects of Beclin 1 silencing on $\mathrm{VK}_{3}$-induced autophagy and apoptosis in human hepatoma SMMC-7721 cells, and to determine the mechanisms underlying the action of Beclin 1 in $\mathrm{VK}_{3}$-induced autophagy and apoptosis.

\section{Materials and methods}

Cell culture and transfection. The human hepatoma cell line SMMC-7721 was maintained in Iscove's modified Dulbecco's medium (IMDM; Invitrogen, USA) supplemented with $10 \%$ fetal bovine serum (FBS) at $37^{\circ} \mathrm{C}$ in a $5 \% \mathrm{CO}_{2}$ incubator.

The specific small interfering RNA sequences were designed for targeting the human Beclin 1 gene (at position 515-533; Genbank accession no. NM_003766) according to the following DNA sequences: forward, 5'-GATCCGTGA ATGAGGATGACAGTGATTCAAGAGATCACTGTCATC CTCATTCATTTTTTGGAAA-3' and reverse, 5'-AGCTTT TCCAAAAAATGAATGAGGATGACAGTGATCTCTTGA ATCACTGTCATCCTCATTCACG-3', The sequences were then cloned into the plasmid of pSilencer 3.1 H1-neo (Austin, USA) to generate the plasmid of pSilence-Beclin 1. Upon reaching $80 \%$ confluence in 6-well plates, the SMMC-7721 cells were transfected with pSilence-Beclin 1 or vehicle control, respectively, using Lipofectamine 2000 Plus reagent (Invitrogen) according to the manufacturer's instructions, and cultured for $48 \mathrm{~h}$. The cells were then trypsinized and harvested. The expression of Beclin 1 in the transfected and untransfected control cells was determined by reverse transcription-polymerase chain reaction (RT-PCR) and Western blotting.

Methyl thiazolyl tetrazolium (MTT) assay. SMMC-7721 cells that had been transfected with pSilence-Beclin 1 or vehicle at $1 \times 10^{4}$ cells/well were cultured in quintuplicate in $10 \%$ FBS IMDM in 96-well plates in the presence or absence of $40 \mu \mathrm{M} \mathrm{VK}_{3}$ (Sigma, USA) at $37^{\circ} \mathrm{C}$ for $18 \mathrm{~h}$. During the last $4 \mathrm{~h}$ of culture, the cells were exposed to $1 \mathrm{mg} / \mathrm{ml} \mathrm{MTT}$ and the generated formazan was dissolved in $150 \mu \mathrm{l}$ DMSO. The absorbance was then measured at $570 \mathrm{~nm}$. Cell viability was expressed as a percentage, and the viability of the cells trans- fected with vehicle and cultured in the absence of $\mathrm{VK}_{3}$ was designated as $100 \%$.

Reverse transcription-polymerase chain reaction. Total RNA was isolated from unmanipulated control SMMC-7721 cells and from cells transfected with pSilence-Beclin 1 or empty vehicle using TRIzol Reagent, according to the manufacturer's instructions (Invitrogen). Total RNA was reverse transcribed into cDNA using the Superscript ${ }^{\circledR}$ VILO $^{\mathrm{TM}}$ cDNA Synthesis kit (Invitrogen). The levels of Beclin 1 mRNA transcripts in these groups of cells were determined by PCR, and the resulting CDNA was used as the template and specific primers. The sequences of primers were forward, 5'-ACCGCAAGATAGTGGCAGAA-3' and reverse, 5'-GCGACCCAGCCTGAAGTTAT-3' for Beclin 1; while forward, 5'-GGGTGATGCTGGTGCTGAGTATGT-3' and reverse, 5'-AAGAATGGGTGTTGCTGTTGAAGTC-3' for glyceraldehyde-3-phosphate dehydrogenase (GAPDH). After 30 cycles of amplification, the PCR products were resolved by agarose gel electrophoresis.

Monodansylcadaverine (MDC) staining. To examine the impact of Beclin 1 knockdown on the autophagic process, the contents of AVs were determined by MDC staining and FACS analysis (21). Briefly, the pSilence-Beclin 1-transfected and vehicle-transfected SMMC-7721 cells at $2 \times 10^{5}$ cells/well were cultured in triplicate in 6-well plates in the presence or absence of $\mathrm{VK}_{3}(40 \mu \mathrm{M})$ for $12 \mathrm{~h}$. The cells were then stained with $10 \mu \mathrm{M} \mathrm{MDC} \mathrm{(Sigma)} \mathrm{at} 37^{\circ} \mathrm{C}$ for $40 \mathrm{~min}$ and fixed with $4 \%$ paraformaldehyde for $15 \mathrm{~min}$. After washing twice with PBS, the intensity of MDC staining in the cells was characterized by FACS analysis on a flow cytometer (Becton Dikinson) at an excitation wavelength of $488 \mathrm{~nm}$. A total of 10,000 cells was measured in each group.

Hoechst 33342 staining. To examine the impact of Beclin 1 knockdown on $\mathrm{VK}_{3}$-induced apoptosis, the pSilenceBeclin 1-transfected and vehicle-transfected SMMC-7721 cells at $2 \times 10^{5}$ cells/well were cultured on coverslips in 6-well plates. Upon reaching $80 \%$ confluence, the cells were treated in triplicate with or without $40 \mu \mathrm{M} \mathrm{VK}_{3}$ for $12 \mathrm{~h}$ and fixed with $4 \%$ paraformaldehyde. After washing with PBS, the cells were stained with Hoechst $33342(10 \mu \mathrm{g} / \mathrm{ml})$ (Sigma) for $15 \mathrm{~min}$, and the coverslips were mounted onto glass slides. Chromatin condensation in different groups of cells was observed under a confocal laser microscope (Olympus FV1000). The number of apoptotic cells was counted in a blinded fashion.

Apoptosis assay. The impact of Beclin 1 knockdown on $\mathrm{VK}_{3}$-induced cell apoptosis was determined by FACS analysis. The pSilence-Beclin 1-transfected and vehicle-transfected SMMC-7721 cells at $2 \times 10^{5}$ cells/well were cultured in triplicate in 6-well plates in the presence or absence of $40 \mu \mathrm{M} \mathrm{VK}_{3}$ for $12 \mathrm{~h}$. Subsequently, the cells were harvested and fixed with cold ethanol (70\% w/v) for $24 \mathrm{~h}$. After washing with PBS, the cells were digested with $1 \%$ RNase $\mathrm{A}$ at $37^{\circ} \mathrm{C}$ for $30 \mathrm{~min}$ and stained with $50 \mu \mathrm{g} / \mathrm{ml}$ propidium iodide (PI; Invitrogen) at $4^{\circ} \mathrm{C}$ for $30 \mathrm{~min}$. The cellular DNA contents were determined by FACS analysis using CellQuest software. Sub-diploid cells were considered apoptotic. 

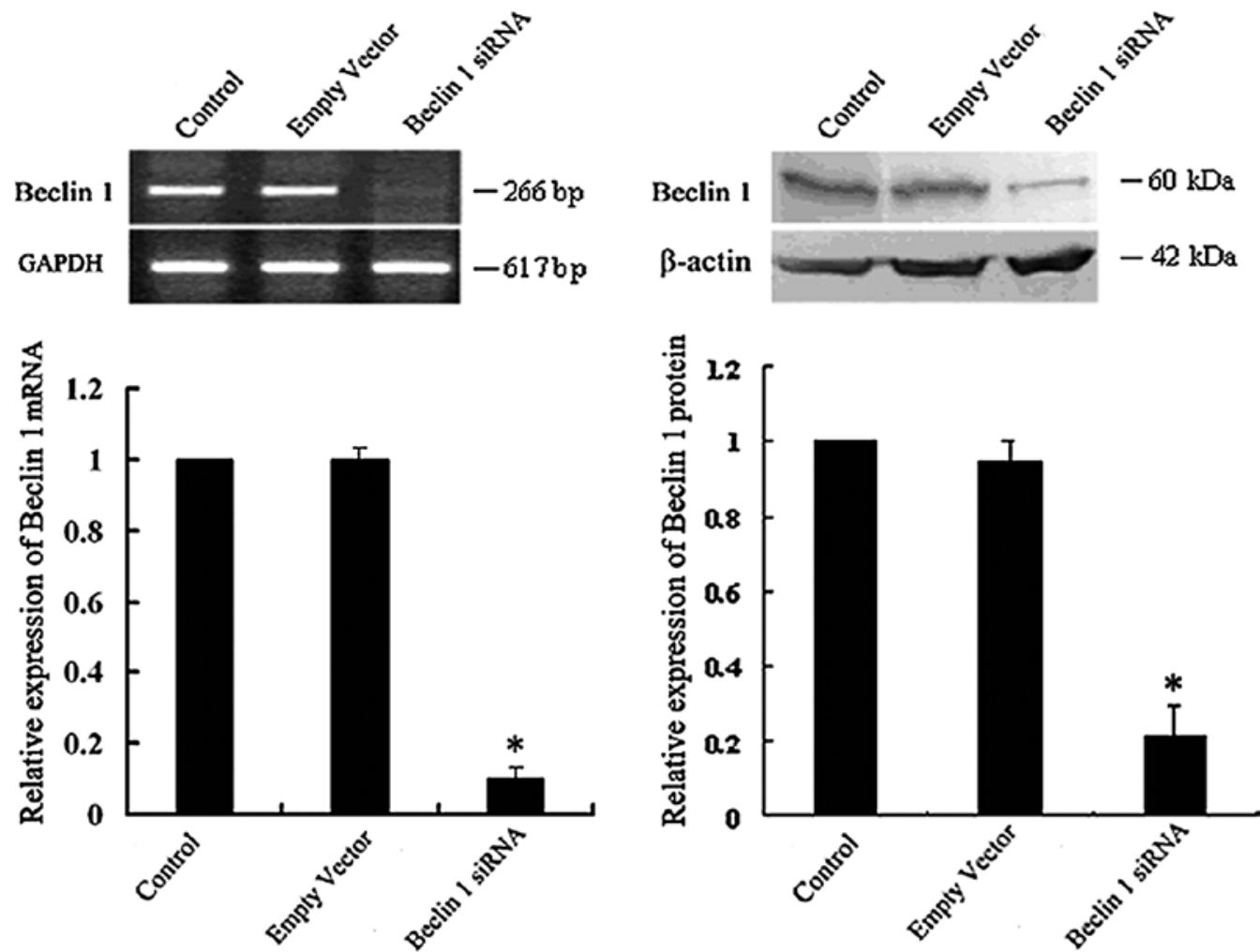

Figure 1. Knockdown of Beclin 1 expression in SMMC-7721 cells. SMMC-7721 cells were transfected with or without vehicle plasmid pSilencer 3.1 or pSilence-Beclin 1 for $48 \mathrm{~h}$. The levels of Beclin $1 \mathrm{mRNA}$ transcripts and protein expression were determined by RT-PCT and Western blotting, followed by semi-quantitative analysis using densitometric scanning (with Beclin 1 expression in untransfected cells designated as 1). Images are representative, and data are expressed as the mean $\pm \mathrm{SD}$ of Beclin 1 expression relative to control GAPDH or $\beta$-actin from three independent experiments. ${ }^{\text {"P }}<0.01$ vs. the control group, determined by the Student's t-test.

Western blotting. After treatment with or without $\mathrm{VK}_{3}(40 \mu \mathrm{M})$ for $12 \mathrm{~h}$, the cells were harvested and the cell lysates were prepared, followed by the determination of protein concentrations using the Bradford assay. The relative levels of proteins in these groups of cells were determined by sodium dodecyl sulfate polyacrylamide gel electrophoresis (SDS-PAGE). Individual cell lysates (30 $\mu \mathrm{g} / \mathrm{lane})$ were separated by $12 \%$ SDS-gel electrophoresis and transferred onto nitrocellulose membranes. The membranes were blocked with 5\% skim milk for $1 \mathrm{~h}$ and washed three times with PBS Tween-20 (PBST). The target proteins were probed with individual antibodies against Beclin 1, cyclin D1, CDK4, Bcl-2, Bcl-xL, cleaved caspase- 3 and internal control $\beta$-actin (Santa Cruz Biotechnology, USA) overnight at $4^{\circ} \mathrm{C}$, respectively. The bound antibodies were detected with horseradish peroxidase (HRP)-conjugated goat anti-rabbit IgG $(1: 2,000)$ (Pierce, USA), with gentle agitation at room temperature for $1 \mathrm{~h}$, and visualized using diaminobenzidine and the Tanon gel imaging system. The levels of each target protein relative to control $\beta$-actin were determined by densitometric scanning.

Statistical analysis. Data shown are expressed as the mean \pm $\mathrm{SD}$. Differences between groups of cells were determined by one-way analysis of variance, followed by the Tukey post-hoc test. Differences between two groups were analyzed by the Student's t-test. A P-value of $<0.05$ was considered statistically significant.

\section{Results}

Knockdown of Beclin 1 expression in SMMC-7721 cells by Beclin 1 siRNA. Beclin 1 is a critical regulator of the survival, autophagy and apoptosis of many types of cells. To determine the impact of Beclin 1 knockdown on the proliferation and apoptosis of human hepatocarcinoma cells, the siRNA sequences specifically targeting the Beclin 1 gene were designed and cloned into pSilencer to generate the pSilence-Beclin 1 plasmid. Following transfection with pSilence-Beclin 1 or empty vehicle, the levels of Beclin 1 mRNA transcripts and protein expression were determined by RT-PCR and Western blotting. As shown in Fig. 1, the transfection of SMMC-7721 cells with vehicle did not affect the expression of Beclin 1, evidenced by similar levels of Beclin 1 expression in unmanipulated and vehicle-transfected SMMC7721 cells. By contrast, transfection with pSilence-Beclin 1 dramatically reduced the levels of Beclin 1 mRNA transcripts and protein expression in SMMC-7721 cells. These data demonstrate that the expressed siRNA effectively silenced Beclin 1 expression in SMMC-7721 cells.

Knockdown of Beclin 1 expression inhibited spontaneous and $V K_{3}$-induced autophagy in SMMC-7721 cells. Spontaneous autophagy is a catabolic process in the cell survival and growth. During the process of autophagy, intracellular organelles and long-lived proteins form the double-membrane 
Table I. Intensity of MDC staining in SMMC-7721 cells.

Group

Fluorescence intensity of MDC staining

\section{Control}

Beclin 1 siRNA

VK3

$\mathrm{VK} 3+$ Beclin 1 siRNA
$103.2 \pm 8.6$

$691.5 \pm 19.5^{\mathrm{a}}$
$33.2 \pm 8.6^{\mathrm{a}}$

$138.3 \pm 9.8^{\mathrm{b}}$

Data are expressed as the mean $\pm \mathrm{SD}$ of each group of cells from three independent experiments. ${ }^{a} \mathrm{P}<0.01$ vs. the control group (vehicletransfected cells without $\mathrm{VK}_{3}$ treatment); ${ }^{\mathrm{b}} \mathrm{P}<0.01$ vs. the $\mathrm{VK} 3$ group.

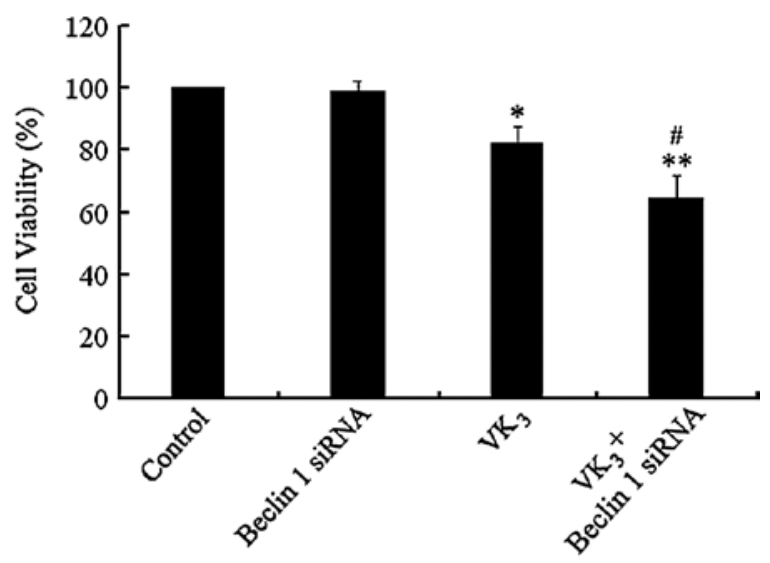

Figure 2. Knockdown of Beclin 1 expression enhances the inhibition of the proliferation of SMMC-7721 cells by $\mathrm{VK}_{3}$. SMMC-7721 cells were transfected with or without the vehicle plasmid or pSilence-Beclin 1, and the effects of $\mathrm{VK}_{3}$ on the proliferation of these cells were determined by the MTT assay. Data are expressed as the mean \pm SD of each group of cells from five independent experiments, and the proliferation of vehicle-transfected cells without $\mathrm{VK}_{3}$ treatment (control) was designated as $100 \%$. The proliferation of control cells was similar to that of unmanipulated SMMC-7721 cells (data not shown). ${ }^{*} \mathrm{P}<0.05$ vs. the control group; ${ }^{* *} \mathrm{P}<0.01$ vs. the control group; ${ }^{\text {P }}<0.01$ vs. the VK3 group.

vesicles of AVs, which can be selectively stained by MDC. To determine the impact of Beclin 1 knockdown on the spontaneous and $\mathrm{VK}_{3}$-induced autophagic process, pSilenceBeclin 1-transfected and vehicle-transfected control cells were treated with or without $\mathrm{VK}_{3}$ for $12 \mathrm{~h}$, and the accumulation of AVs in SMMC-7721 cells was determined by MDC staining. As shown in Table I, the intensity of MDC staining in the Beclin 1-silenced cells was significantly lower than that in the vehicle-transfected controls $(\mathrm{P}<0.01)$. Following treatment with $\mathrm{VK}_{3}$, there was an approximately 6-fold increase in the number of control cells undergoing the autophagic process, and significantly increased levels of MDC staining were detected in $\mathrm{VK}_{3}$-treated control cells, indicating that $\mathrm{VK}_{3}$ promoted the autophagic process in SMC-7721 cells in vitro. By contrast, the average intensity of MDC staining in $\mathrm{VK}_{3}$-treated Beclin 1-silenced cells was dramatically reduced, as compared to that in $\mathrm{VK}_{3}$-treated control cells. Collectively, the data indicated that the knockdown of Beclin 1 expression inhibited the spontaneous and $\mathrm{VK}_{3}$-promoted autophagic process in SMMC-7721 cells in vitro.
A

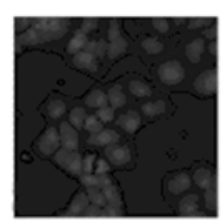

Control

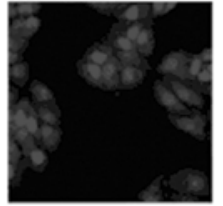

Beclin 1 siRNA

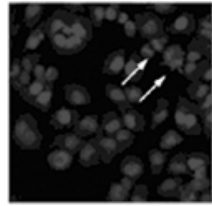

$\mathrm{VK}_{3}$

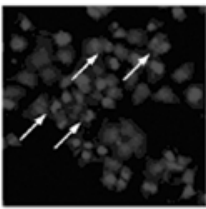

$\mathrm{VK}_{3}+$ Beclin 1 SiRNA

\section{B}

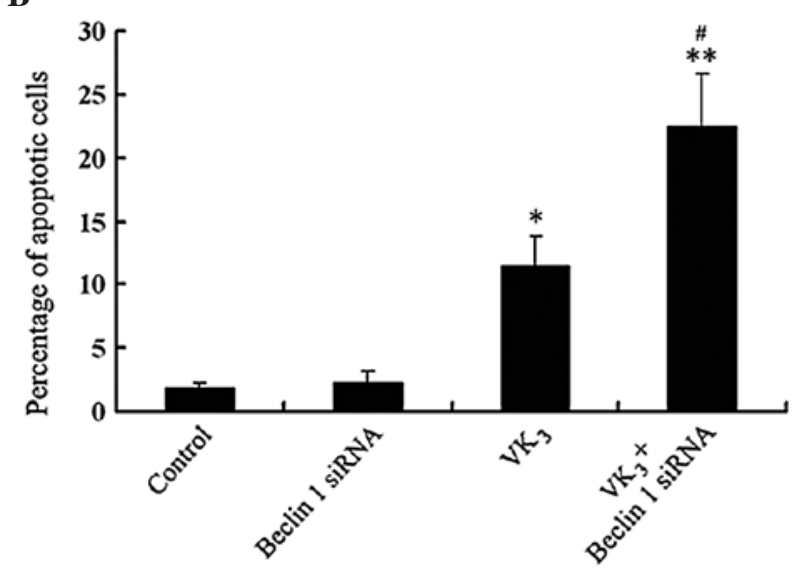

Figure 3. Knockdown of Beclin 1 expression enhances $\mathrm{VK}_{3}$-induced apoptosis in SMMC-7721 cells. The vehicle-transfected control and Beclin 1-silenced SMMC-7721 cells were treated with or without $\mathrm{VK}_{3}$, and the apoptotic cells were characterized by Hoechst 33342 staining. Images are representative, and data are expressed as the mean \pm SD of each group of cells from three independent experiments. ${ }^{*} \mathrm{P}<0.05$ vs. the control group; ${ }^{* *} \mathrm{P}<0.01$ vs. the control group; ${ }^{*} \mathrm{P}<0.01$ vs. the $\mathrm{VK}_{3}$ group.

Knockdown of Beclin 1 expression enhanced $V K_{3}$-induced inhibition of SMMC-7721 cell proliferation. The MTT assay was used to examine whether the knockdown of Beclin 1 affects the inhibition of the survival and proliferation of SMMC-7721 cells by $\mathrm{VK}_{3}$ (Fig. 2). It was observed that the percentage survival of Beclin 1-silenced cells was similar to that of vehicle-transfected controls cells, suggesting that the knockdown of Beclin 1 expression did not significantly affect the survival and proliferation of SMMC-7721 cells in vitro. Notably, treatment with $\mathrm{VK}_{3}$ reduced the overall survival rates of vehicle-transfected cells by $\sim 20 \%$. The same treatment decreased the survival rates of Beclin 1-silenced cells to $\sim 60 \%$, which was significantly lower than in the $\mathrm{VK}_{3}$-untreated control cells $(\mathrm{P}<0.01)$. These data indicate that the knockdown of Beclin 1 expression enhanced the inhibitory effect of $\mathrm{VK}_{3}$ on the survival and proliferation of SMMC-7721 cells in vitro.

Knockdown of Beclin 1 expression promotes $V K_{3}$-induced apoptosis of SMMC-7721 cells. To determine potential mechanisms of Beclin 1, Hoechst 33342 staining was used to examine whether the knockdown of Beclin 1 expression regulates the spontaneous and $\mathrm{VK}_{3}$-induced apoptosis of SMMC-7721 cells (Fig. 3). Very few cells were observed to undergo spontaneous apoptosis, as evidenced by the chromatin-condensed nuclei, regardless of whether the cells had been transfected with the vehicle or pSilence-Beclin 1. This indicated that the knockdown of Beclin 1 expression did not promote the spontaneous apoptosis of SMMC-7721 cells under the experi- 


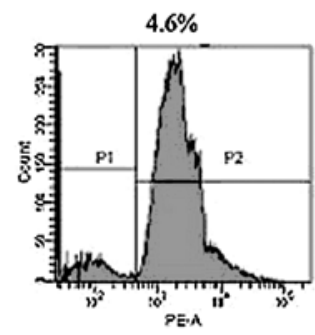

Control

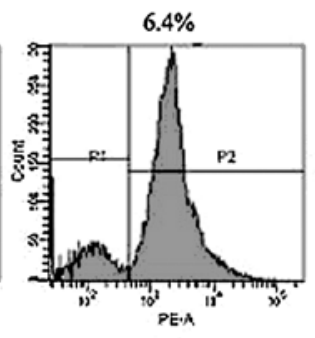

Beclin 1 siRNA

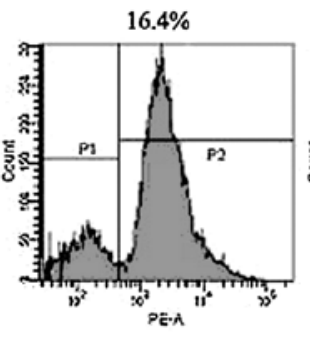

$\mathrm{VK}_{3}$

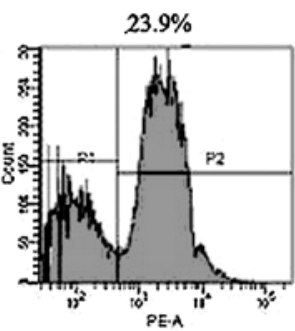

$\mathrm{VK}_{3}+$ Beclin 1 siRNA

Figure 4. Flow cytometric analysis of spontaneous and $\mathrm{VK}_{3}$-induced apoptosis in SMMC-7721 cells. The vehicle-transfected control and Beclin 1-silenced SMMC-7721 cells were treated with or without $\mathrm{VK}_{3}$ and stained with PI. Apoptotic cells were characterized by flow cytometric analysis. Data are representative of each group of cells, and the $\mathrm{P} 1$ phase represents apoptotic cells.

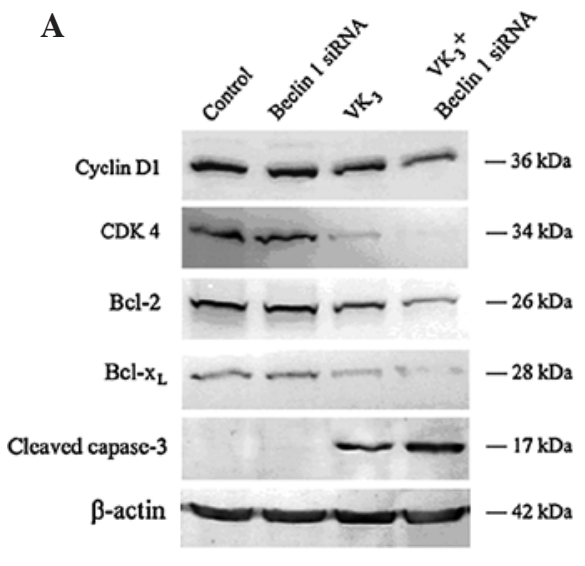

C

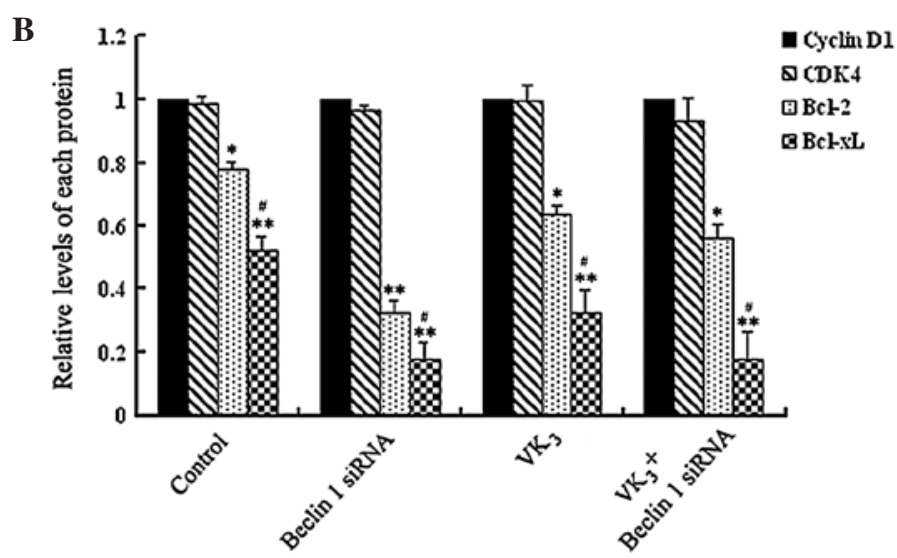

Figure 5. Knockdown of Beclin 1 expression modulates the $\mathrm{VK}_{3}$-induced down-regulation of cyclin D1, CDK4, Bcl-2 and Bcl-xL expression and active caspase-3 in SMMC-7721 cells. The vehicle-transfected control and Beclin 1-silenced SMMC-7721 cells were treated with or without $\mathrm{VK}_{3}$, and the expression of cyclin D1, CDK4, Bcl-2, Bcl-xL and active caspase-3 was determined by Western blotting using specific antibodies. The relative levels of each protein to control $\beta$-actin in individual groups of cells were determined by densitometric scanning. (A) Representative images. (B) Semi-quantitative analysis of protein expression. The levels of each protein in control cells were designated as 1. (C) Semi-quantitative analysis of active caspase-3. The levels of active caspase-3 in control cells were designated as $100 \%$. Data are expressed as the mean \pm SD of the levels of each protein relative to control $\beta$-actin. " $\mathrm{P}<0.05 \mathrm{vs}$. the control group; ${ }^{* *} \mathrm{P}<0.01$ vs. the control group; ${ }^{*} \mathrm{P}<0.01$ vs. the $\mathrm{VK}_{3}$ group.

mental conditions. Quantitative analysis of apoptotic cells revealed that the frequency of apoptotic cells was significantly higher in $\mathrm{VK}_{3}$-treated control cells than in untreated controls $(\mathrm{P}<0.05)$. Furthermore, the frequency of apoptotic $\mathrm{VK}_{3}$-treated Beclin 1-silenced SMMC-7721 cells was significantly elevated, by $200 \%$, as compared to $\mathrm{VK}_{3}$-treated vehicle-transfected control cells (Fig. 3B). Similar results were observed using PI staining and flow cytometry analysis (Fig. 4). While there was no significant difference in the number of apoptotic cells between vehicle-transfected and Beclin 1-silenced SMMC7721 cells $(4.6 \pm 0.7$ vs. $6.4 \pm 0.9 \%, P>0.05)$, treatment with $\mathrm{VK}_{3}$ significantly induced the apoptosis of both vehicle-transfected and Beclin 1-silenced SMMC-7721 cells. Notably, the number of apoptotic $\mathrm{VK}_{3}$-treated Beclin 1-silenced SMMC-7721 cells was significantly higher than that of apoptotic $\mathrm{VK}_{3}$-treated vehicle-treated controls $(23.9 \pm 5.4$ vs. $16.4 \pm 2.7 \%, \mathrm{P}<0.01)$. 
Apparently, the knockdown of Beclin 1 expression enhanced the $\mathrm{VK}_{3}$-induced apoptosis of SMMC-7721 cells in vitro.

Knockdown of Beclin 1 expression regulates $V K_{3}$-modulated expression of cyclin D1,CDK 4, Bcl-2 and Bcl-xL proteins and caspase-3 activation in SMMC-7721 cells. To further determine the molecular mechanisms by which Beclin 1 silencing regulated $\mathrm{VK}_{3}$-modulated cell survival and apoptosis, cyclin D1, CDK4, Bcl-2 and Bcl-xL expression as well as caspase-3 activation were determined by Western blotting. First, the knockdown of Beclin 1 expression appeared to affect neither the expression of cyclin D1, CDK4, Bcl-2 or Bcl-xL, nor to induce caspase-3 activation, since the relative levels of cyclin D1, CDK4, Bcl-2 and Bcl-xL in Beclin 1-silenced cells were indistinguishable from those in vehicle-transfected cells, and since there were no significantly elevated levels of caspase-3 activation in either of the groups of cells (Fig. 5). Furthermore, treatment with $\mathrm{VK}_{3}$ significantly inhibited the expression of cyclin D1, CDK4, Bcl-2 and Bcl-xL, accompanied by dramatically elevated levels of caspase- 3 activation in vehicle-transfected cells. Of note, treatment with $\mathrm{VK}_{3}$ dramatically reduced cyclin D1, CDK4, Bcl-2 and Bcl-xL expression, in particular CDK4 and $\mathrm{Bcl}-\mathrm{xL}$ expression, and induced strong activation of caspase-3 in Beclin 1-silenced cells. The data indicate that the knockdown of Beclin 1 did not significantly modulate cyclin D1, CDK4, Bcl-2 and Bcl-xL expression, but did significantly enhance $\mathrm{VK}_{3}$-induced down-regulation of cyclin D1, CDK4, Bcl-2 and Bcl-xL expression and caspase-3 activation in SMMC-7721 cells in vitro.

\section{Discussion}

In this study, we examined the impact of Beclin 1 knockdown on spontaneous and $\mathrm{VK}_{3}$-modulated hepatoma cell proliferation and autophagy in SMMC-7721 cells in vitro. A Beclin 1-specific siRNA approach was employed to successfully knockdown Beclin 1 expression in SMMC-7721 cells. The levels of Beclin $1 \mathrm{mRNA}$ transcripts and proteins were reduced by 93 and $80 \%$, respectively, in Beclin 1-specific siRNA-expressed cells, as compared to the vehicle-transfected cells. We found that the proliferation, viability and frequency of spontaneous apoptosis in Beclin 1-silenced cells were similar to those in vehicle-transfected control cells. Furthermore, the relative levels of cyclin D1, CDK4, Bcl-2 and Bcl-xL in Beclin 1-silenced cells were also comparable to those in control cells, accompanied by very low levels of active caspase- 3 in both groups of cells. These data are consistent with previously reported results (19), and indicate that the knockdown of Beclin 1 expression did not significantly affect hepatoma cell proliferation and spontaneous apoptosis. However, our data were in disagreement with the finding that the partial downregulation of Beclin 1 expression augmented the apoptosis of HepG2 cells in vitro (19). This difference may be due to the use of different hepatoma cell lines or different experimental conditions. The lack of significant regulatory effects of the knockdown of Beclin 1 expression on the proliferation and spontaneous apoptosis of human hepatoma cells suggests that Beclin 1 may be an upstream regulator of the development of hepatoma. Notably, the intensity of MDC staining in Beclin 1-silenced cells was significantly lower than that of the vehicle-transfected controls, indicating that the knockdown of Beclin 1 expression inhibited the spontaneous autophagy of hepatoma cells in vitro. Beclin 1 is a tumor suppressor and its deficient expression has been associated with the development of tumors in a clinical setting $(22,23)$. The significant effect of Beclin 1 silencing on the inhibition of spontaneous hepatoma cell autophagy further demonstrates that Beclin 1 is a critical regulator of autophagy in human hepatoma cells (18).

$\mathrm{VK}_{3}$ is a potent inducer of oxidative stress and has strong anti-tumor activities $(24,25) . \mathrm{VK}_{3}$ inhibition of the growth of tumor cells in vitro and in vivo (5-7) is associated with the induction of cell cycle arrest and caspase-dependent apoptosis $(1,4)$. We examined the impact of Beclin 1 knockdown on $\mathrm{VK}_{3}$-mediated growth inhibition, apoptosis and autophagy in human hepatoma cells, and found that treatment with $\mathrm{VK}_{3}$ significantly inhibited the growth of SMMC-7721 cells and triggered a high frequency of hepatoma cell apoptosis in vitro, accompanied by high levels of caspase-3 activation. Indeed, $\mathrm{VK}_{3}$ augments doxorubicin- and Fas-induced apoptosis in hepatoma-derived HepG2 cells (19). These regulatory effects of $\mathrm{VK}_{3}$ were likely mediated by the inhibition of the expression of cyclin D1, CDK4, Bcl-2 and Bcl-xL in SMMC-7721 cells, similar to previous reports using other human hepatoma cell lines $(4-7,19)$. Notably, treatment with $\mathrm{VK}_{3}$ promoted hepatoma cell autophagy in vitro, similar to a previous report suggesting that VK2 promoted autophagy, thus inhibiting the growth of cholangiocellular carcinoma cells (8). Therefore, $\mathrm{VK}_{3}$ may induce apoptosis and autophagy and mitigate the growth and survival of human hepatoma cells in vitro.

We found that Beclin 1-silenced SMMC-7721 cells were more sensitive to $\mathrm{VK}_{3}$-induced apoptosis, but resistant to autophagy in vitro. Evidently, $\mathrm{VK}_{3}$ treatment triggered a significantly higher frequency of Beclin 1-silenced SMMC7721 cells undergoing apoptosis. Furthermore, $\mathrm{VK}_{3}$ treatment dramatically reduced the expression of cyclin D1, CDK4, $\mathrm{Bcl}-2$ and $\mathrm{Bcl}-\mathrm{xL}$ expression in Beclin 1-silenced hepatoma cells, accompanied by higher levels of active caspase- 3 . Apparently, the knockdown of Beclin 1 expression enhanced the $\mathrm{VK}_{3}$-induced hepatoma cell apoptosis in vitro. In addition, we found that the knockdown of Beclin 1 expression inhibited $\mathrm{VK}_{3}$-induced autophagy in SMMC-7721 cells. These data support the notion that Beclin 1 is a positive regulator of autophagy, supporting survival and preventing apoptosis in many types of cells $(14,22)$. Indeed, autophagy has been found to delay sulindac sulfide-induced apoptosis by sequestering mitochondrial death-promoting factors in colon cancer HT-29 cells (26). Furthermore, the inhibition of autophagy using siRNAs targeting genes that positively regulate autophagy or by treatment with inhibitors specific for autophagy, promotes apoptosis (11), and the inhibition of paraquat-induced autophagy accelerates the apoptotic process in neuroblastoma SH-SY5Y cells (27). It is possible that $\mathrm{VK}_{3}$ or its associated signaling events may modulate the expression and activity of Beclin 1 and related signaling in hepatoma cells, promoting hepatoma cell autophagy. However, the precise mechanisms underlying the action of $\mathrm{VK}_{3}$ during the process of autophagy remain to be further determined.

Beclin 1 was initially characterized as a Bcl-2-binding protein (28). Subsequent studies showed that Beclin 1 also interacts with $\mathrm{Bcl}-\mathrm{xL}$ (19). Bcl-2/Bcl-xL inhibit apoptosis 
by interfering with the action of pro-apoptotic proteins, and regulate autophagy by interacting with Beclin 1 (14). The interaction of Beclin 1 with either Bcl-2 or Bcl-xL may also be essential for the anti-apoptotic effects of Beclin 1 (18). We examined the effects of Beclin 1 silencing on $\mathrm{VK}_{3}$-regulated $\mathrm{Bcl}-2$ and Bcl-xL expression in SMMC-7721 cells. The levels of Bcl-2 and Bcl-xL expression were found to be significantly lower in Beclin 1-silenced SMMC-7721 cells than in the Beclin 1-expressing cells, indicating that Beclin 1 may protect the cells from $\mathrm{VK}_{3}$-induced down-regulation of Bcl-2 and Bcl-xL expression in hepatoma cells. Given that $\mathrm{VK}_{3}$ promoted strong autophagy in Beclin 1-expressing, but not in Beclin 1-silenced, SMMC-7721 cells, $\mathrm{VK}_{3}$-promoted down-regulation of Bcl-2 and Bcl-xL expression may not be associated with its ability to promote autophagy in SMMC-7721 cells in vitro. Conceivably, Bcl-2 and Bcl-xL may have little effect on the regulation of $\mathrm{VK}_{3}$-induced autophagy in SMMC-7721 cells. In addition, we observed that the knockdown of Beclin 1 expression enhanced $\mathrm{VK}_{3}$-induced down-regulation of cyclin D1 and CDK4 expression, which are positive regulators of the cell cycle process. The down-regulation of cyclin D1 and CDK4 expression is usually related to cell cycle arrest, particularly at the G1 phase. Therefore, Beclin 1 may protect cyclin D1 and CDK4 expression from $\mathrm{VK}_{3}$ down-regulation in SMMC-7721 cells in vitro, promoting the cell cycle and survival.

In conclusion, our study provides evidence that the knockdown of Beclin 1 expression induces resistance to spontaneous and $\mathrm{VK}_{3}$-induced autophagy in SMMC-7731 cells in vitro. This supports the notion that Beclin 1 is a positive regulator of autophagy. Furthermore, the knockdown of Beclin 1 expression enhanced $\mathrm{VK}_{3}$-induced apoptosis in SMMC-7721 cells, which was likely mediated by the down-regulation of the expression of cell cycle regulators cyclin D1 and CDK4 and anti-apoptotic Bcl-2 and Bcl-xL in SMMC-7721 cells. Conceivably, Beclin 1 may positively promote autophagy, preventing apoptosis in hepatoma cells. Therefore, our data suggest that the inhibition of autophagy may promote hepatoma cell apoptosis. Our findings may provide a basis for the design of novel therapeutic strategies for the treatment of hepatoma.

\section{Acknowledgements}

I thank my colleagues for the kind help during this study.

\section{References}

1. Hitomi M, Yokoyama F, Kita Y, Nonomura T, Masaki T, Yoshiji H, Inoue H, Kinekawa F, Kurokohchi K, Uchida N, Watanabe S and Kuriyama S: Antitumor effects of vitamins K1, $\mathrm{K} 2$ and $\mathrm{K} 3$ on hepatocellular carcinoma in vitro and in vivo. Int J Oncol 26: 713-720, 2005.

2. Von Gruenigen VE, Jamison JM, Gilloteaux J, Lorimer HE, Summers M, Pollard RR, Gwin CA and Summers JL: The in vitro antitumor activity of vitamins $\mathrm{C}$ and $\mathrm{K} 3$ against ovarian carcinoma. Anticancer Res 23: 3279-3287, 2003.

3. Osada S, Tomita H, Tanaka Y, Tokuyama Y, Tanaka H, Sakashita F and Takahashi T: The utility of vitamin K3 (menadione) against pancreatic cancer. Anticancer Res 28: 45-50, 2008.

4. Markovits J, Wang Z, Carr BI, Sun TP, Mintz P, Le Bret M, Wu CW and Wu FY: Differential effects of two growth inhibitory $\mathrm{K}$ vitamin analogs on cell cycle regulating proteins in human hepatoma cells. Life Sci 72: 2769-2784, 2003.

5. Caricchio R, Kovalenko D, Kaufmann WK and Cohen PL: Apoptosis provoked by the oxidative stress inducer menadione (Vitamin K(3)) is mediated by the Fas/Fas ligand system. Clin Immunol 93: 65-74, 1999.
6. Ogawa M, Nakai S, Deguchi A, Nonomura T, Masaki T, Uchida N, Yoshiji H and Kuriyama S: Vitamins K2, K3 and K5 exert antitumor effects on established colorectal cancer in mice by inducing apoptotic death of tumor cells. Int $\mathbf{J}$ Oncol 31: 323-331, 2007.

7. Akiyoshi T, Matzno S, Sakai M, Okamura N and Matsuyama K: The potential of vitamin K3 as an anticancer agent against breast cancer that acts via the mitochondria-related apoptotic pathway. Cancer Chemother Pharmacol 65: 143-150, 2009.

8. Enomoto M, Tsuchida A, Miyazawa K, Yokoyama T, Kawakita H, Tokita H, Naito M, Itoh M, Ohyashiki K and Aoki T: Vitamin K2-induced cell growth inhibition via autophagy formation in cholangiocellular carcinoma cell lines. Int J Mol Med 20: 801-808, 2007.

9. Ogier-Denis E and Codogno P: Autophagy: a barrier or an adaptive response to cancer. Biochim Biophys Acta 1603: 113-128, 2003.

10. Bursch W: The autophagosomal-lysosomal compartment in programmed cell death. Cell Death Differ 8: 569-581, 2001.

11. Boya P, González-Polo RA, Casares N, Perfettini JL, Dessen P, Larochette N, Métivier D, Meley D, Souquere S, Yoshimori T, Pierron G, Codogno P and Kroemer G: Inhibition of macroautophagy triggers apoptosis. Mol Cell Biol 25: 1025-1040, 2005.

12. Bursch W, Hochegger K, Török L, Marian B and Ellinger A: Autophagic and apoptotic types of programmed cell death exhibit different fates of cytoskeletal filaments. J Cell Sci 113: 1189-1198, 2000

13. Majeski AE and Dice JF: Mechanisms of chaperone-mediated autophagy. Int J Biochem Cell Biol 36: 2435-2444, 2004.

14. Zhang H, Kong X, Kang J, Su J, Li Y, Zhong J and Sun L: Oxidative stress induces parallel autophagy and mitochondria dysfunction in human glioma U251 cells. Toxicol Sci 110: 376-388, 2009.

15. Aita VM, Liang XH, Murty VV, Pincus DL, Yu W, Cayanis E, Kalachikov S, Gilliam TC and Levine B: Cloning and genomic organization of Beclin 1, a candidate tumor suppressor gene on chromosome 17q21. Genomics 59: 59-65, 1999.

16. Yue Z, Jin S, Yang C, Levine AJ and Heintz N: Beclin 1, an autophagy gene essential for early embryonic development, is a haploinsufficient tumor suppressor. Proc Natl Acad Sci USA 100: 15077-15082, 2003.

17. Pattingre S, Tassa A, Qu X, Garuti R, Liang XH, Mizushima N, Packer M, Schneider MD and Levine B: Bcl-2 antiapoptotic proteins inhibit Beclin 1-dependent autophagy. Cell 122: 927-939, 2005

18. Liang XH, Kleeman LK, Jiang HH, Gordon G, Goldman JE, Berry G, Herman B and Levine B: Protection against fatal Sindbis virus encephalitis by Beclin, a novel Bcl-2-interacting protein. J Virol 72: 8586-8596, 1998.

19. Daniel F, Legrand A, Pessayre D, Vadrot N, Descatoire V and Bernuau D: Partial Beclin 1 silencing aggravates doxorubicin- and Fas-induced apoptosis in HepG2 cells. World J Gastroenterol 12: 2895-2900, 2006.

20. Furuya D, Tsuji N, Yagihashi A and Watanabe N: Beclin 1 augmented cis-diamminedichloroplatinum induced apoptosis via enhancing caspase-9 activity. Exp Cell Res 307: 26-40, 2005.

21. Biederbick A, Kern HF and Elsasser HP: Monodansylcadaverine (MDC) is a specific in vivo marker for autophagic vacuoles. Eur J Cell Biol 66: 3-14, 1995.

22. Sun Q, Fan W and Zhong Q: Regulation of Beclin 1 in autophagy. Autophagy 5: 713-716, 2009.

23. Maiuri MC, Tasdemir E, Criollo A, Morselli E, Vicencio JM, Carnuccio R and Kroemer G: Control of autophagy by oncogenes and tumor suppressor genes. Cell Death Differ 16: 87-93, 2009.

24. Caricchio R, Kovalenko D, Kaufmann WK and Cohen PL: Apoptosis provoked by the oxidative stress inducer menadione (Vitamin K3) is mediated by the Fas/Fas ligand system. Clin Immunol 93: 65-74, 1999

25. Park SY, Chang I, Kim JY, Kang SW, Park SH, Singh K and Lee MS: Resistance of mitochondrial DNA-depleted cells against cell death: role of mitochondrial superoxide dismutase. J Biol Chem 279: 7512-7520, 2004

26. Bauvy C, Gane P, Arico S, Codogno P and Ogier-Denis E: Autophagy delays sulindac sulfide-induced apoptosis in the humanintestinal colon cancer cell line HT-29. Exp Cell Res 268: 139-149, 2001

27. González-Polo RA, Niso-Santano M, Ortíz-Ortíz MA, et al: Inhibition of paraquat-induced autophagy accelerates the apoptotic cell death in neuroblastoma SH-SY5Y cells. Toxicol Sci 97: 448-458, 2007.

28. Liang XH, Jackson S, Seaman M, Brown K, Kempkes B, Hibshoosh H and Levine B: Induction of autophagy and inhibition of tumorigenesis by Beclin 1. Nature 402: 672-676, 1999. 